\title{
0 cuidado de enfermagem e o cateter de Hickman: a busca de evidências*
}

\author{
Nursing care and Hickman's catheter: the search for evidence \\ El cuidado de enfermeria y el catéter Hickman: la búquela de evidencias
}

\author{
Renata Cristina de Campos Pereira Silveira ${ }^{1}$, Cristina Maria Galvão²
}

\begin{abstract}
RESUMO
Introdução: Os pacientes submetidos ao transplante de medula óssea (TMO) necessitam de um acesso venoso seguro para a infusão da medula óssea. A implantação de um cateter venoso central é parte da terapêutica, sendo o de Hickman o mais utilizado atualmente; entretanto, sua presença impõe riscos, sendo a infecção, o mais preocupante. Objetivo: Revisão integrativa da literatura, que teve como objetivo buscar e avaliar as evidências sobre os cuidados de enfermagem relacionados ao cateter de Hickman. Método: Para a seleção dos artigos utilizamos as bases de dados Lilacs, Medline, Cinahl e o periódico Bone Marrow Transplantation, e a amostra constituiu-se de 18 artigos. Resultados: O curativo recomendado é o de poliuretano trocado a cada 7 dias. O método de coleta de sangue observado foi o de descarte, sendo que a dosagem de ciclosporina não deve ser coletada da mesma via onde foi infundida. A redução do número de manipulações do cateter é considerada uma medida eficaz na prevenção e no controle de infecção. Considerações finais: As evidências extraídas dos estudos analisados podem auxiliar a implementação de cuidados de enfermagem eficazes relacionados ao cateter de Hickman.
\end{abstract}

Descritores: Transplante de medula óssea; Cateterismo venoso central; Cuidados de enfermagem

\begin{abstract}
Background: Patients submitted to Bone Marrow Transplantation (BMT) need a safe venous access for the infusion of bone marrow. The implantation of a central venous catheter is a part of therapy, with Hickman's catheter as the most commonly used type; however, its presence entails risks, the most preoccupying of which is infection. Objective: Integrative literature review aimed to look for and evaluate evidence on nursing care related to Hickman's catheter. Method: Articles were selected from the Lilacs, Medline and Cinahl databases and from the journal Bone Marrow Transplantation. The sample consisted of 18 articles. Results: Polyurethane dressings are recommended, to be changed every 7 days. The observed blood collection method was through discarding, in which the cyclosporine dose should not be collected from the same pathway it was infused in. Reducing the number of catheter manipulations is considered an efficient measure for infection prevention and control. Conclusion: The evidence taken from the studies that were analyzed can be of help in the implementation of efficient nursing care related to Hickman's catheter.
\end{abstract}

Keywords: Bone marrow transplantation; Catheterization, central venous; Nursing care

\section{RESUMEN}

Introdución: Los pacientes sometidos al trasplante de médula ósea (TMO) necesitan de un acceso venoso seguro para la infusión de la médula ósea. La implantación de un catéter venoso central hace parte de la terapéutica siendo el de Hickman el más utilizado actualmente; sin embargo, su presencia impone riesgos a los pacientes, el más preocupante de los cuales es la infección. Objetivo: La finalidad de esta revisión integradora de la literatura fue buscar y evaluar las evidencias sobre los cuidados de enfermería relacionados al catéter Hickman. Método: Para seleccionar los artículos utilizamos las bases de datos Lilacs, Medline, Cinahl y la publicación Bone Marrow Transplantation, y la muestra consistió en 18 artículos. Resultados: El vendaje recomendado es el de poliuretano cambiado cada 7 días. El método de colecta de sangre observado fue el de desecho, en el que el dosaje de ciclosporina no debe ser colectado de la misma vía donde fue infundido. La reducción del número de manipulaciones del catéter es considerada una medida eficaz en la prevención y en el control de infección. Las evidencias extraídas de los estudios analizados pueden auxiliar la implementación de cuidados de enfermería eficaces relacionados al catéter Hickman.

Descriptores: Trasplante de médula ósea; Cateterismo venoso central; Cuidados de enfermería

Trabalho extraído da dissertação de mestrado Silveira RCCP. O cuidado de enfermagem e o cateter de Hickman: a busca de evidências. Escola de Enfermagem, Universidade de São Paulo - USP - Ribeirão Preto (SP), Brasil.

1 Enfermeira do Departamento de Enfermagem Geral e Especializada da Escola de Enfermagem, Universidade de São Paulo - USP - Ribeirão Preto (SP), Brasil. Centro Colaborador da OMS para o desenvolvimento da pesquisa em enfermagem. Mestre em Enfermagem Fundamental.

2 Professor Associado. Escola de Enfermagem, Universidade de São Paulo - USP - Ribeirão Preto (SP), Brasil, Centro Colaborador da OMS para o desenvolvimento da pesquisa em enfermagem. 


\section{INTRODUÇÃO}

O transplante de medula óssea (TMO) é um procedimento médico, relativamente novo, que está sendo usado no tratamento de doenças que se acreditava serem incuráveis. O objetivo é corrigir um defeito quantitativo ou qualitativo da medula óssea. É utilizado no tratamento de doenças hematológicas malignas e não-malignas, imunodeficiências, erros inatos de metabolismo e de tumores sólidos ${ }^{(1)}$.

Atualmente, o TMO também tem se destacado como alternativa no tratamento de doença auto-imune, cujo êxito foi atribuído a observações de alguns casos de pacientes portadores de doença maligna, com doença auto-imune associada e que, após a realização do TMO, apresentaram remissão da patologia auto-imune ${ }^{(1)}$.

O TMO é considerado um procedimento de risco devido às complicações, cuja freqüência depende do tipo de transplante efetuado, bem como da idade e da condição clínica subjacente do indivíduo.

A indicação do uso de cateter de Hickman em pacientes submetidos ao TMO ocorre principalmente por dispensar a punção percutânea, monitorização da pressão venosa central, e por ser adequado à infusão de grandes quantidades de fluidos, simultaneamente, e de soluções por tempo prolongado como, por exemplo, a nutrição parenteral, além de garantir a infusão da medula óssea sem comprometer o enxerto.

A literatura aponta que a incidência de complicações que levam à necessidade de retirada do cateter de Hickman é de aproximadamente $30 \%$, sendo que as mais frequientes são: infecção e migração do cateter e trombose ${ }^{(2)}$.

Microrganismos podem colonizar o cateter induzidos pela quebra na integridade cutânea. A realização de curativo sobre o óstio de saída, onde a integridade da pele está interrompida, auxilia na prevenção das complicações infecciosas. As infecções relacionadas ao cateter podem ser classificadas em três tipos: infecção do óstio de saída, infecção do túnel subcutâneo (tunelite) e septicemia relacionada ao cateter $^{(3)}$.

Por outro lado, a patogenia da infecção em cateteres tunelizados está mais comumente associada à contaminação do "hub" e conseqüente infecção intraluminal, confirmando que o número de manipulações do cateter é um importante fator de risco. Assim, um treinamento adequado dos profissionais de saúde para a realização dos procedimentos de manipulação pode ser uma das medidas para prevenir as bacteremias relacionadas ao cateter venoso central ${ }^{(4)}$.

Diariamente, o cateter de Hickman é intensamente manipulado, na maioria das vezes pela equipe de enfermagem, e a infecção é uma das complicações mais freqüentes que levam à retirada do cateter. Dessa forma, evidencia-se a necessidade de que os membros da equi- pe de enfermagem sejam capacitados, a fim de prestarem cuidados que minimizem os riscos inerentes à utilização deste cateter.

Frente ao exposto, buscamos na literatura um referencial teórico que pudesse fundamentar o presente estudo, selecionamos a prática baseada em evidências (PBE), que é uma abordagem que incorpora as evidências oriundas de pesquisas, a competência clínica do profissional e as preferências do cliente para a tomada da decisão sobre a assistência à saúde. Consiste em um processo de busca, avaliação e aplicação de evidências científicas para o tratamento e gerenciamento da saúde. O cuidado é guiado por meio de resultados de pesquisas, consenso de especialistas ou pela combinação de ambos ${ }^{(5)}$.

No presente estudo, utiliza-se como método a revisão integrativa da literatura, a qual tem como finalidade reunir e sintetizar o conhecimento científico já produzido sobre o tema investigado, ou seja, permite buscar, avaliar e sintetizar as evidências disponíveis para a sua incorporação na prática. Para a construção da revisão integrativa, utilizamos como referência estudos que detalham este método de pesquisa ${ }^{(6-7)}$.

O objetivo do estudo consiste em buscar e avaliar as evidências disponíveis na literatura sobre os cuidados de enfermagem relacionados ao cateter de Hickman, após a implantação no paciente submetido ao TMO.

\section{MÉTODOS}

Para a elaboração da revisão integrativa as seguintes fases foram percorridas: identificação do tema, amostragem ou busca na literatura, categorização dos estudos, avaliação dos estudos, interpretação dos resultados e a síntese do conhecimento evidenciado nos artigos analisados ou apresentação da revisão integrativa.

A pergunta norteadora da presente revisão integrativa consistiu em: quais são os cuidados de enfermagem relacionados ao cateter de Hickman após a sua implantação no paciente submetido ao TMO?

A seleção dos artigos foi por meio das bases de dados Literatura Latino-Americana e do Caribe em Ciências da Saúde (LILACS), Cumulative Index to Nursing and Allied Health Literature (CINAHL) e Medical Literature Analysis and Retrieval Sistem on-line (MEDLINE) e do periódico Bone Marrow Transplantation (BMT), sendo que as palavras-chave foram: transplante de medula óssea, cateter venoso central, cuidado de enfermagem e intervenção de enfermagem.

Os critérios de inclusão dos artigos da presente revisão integrativa foram: artigos que abordem os cuidados de enfermagem relacionados ao cateter de Hickman após a sua implantação no paciente submetido ao TMO e artigos publicados em inglês, espanhol e português. 
Assim, selecionamos e analisamos dezoito artigos conforme os critérios de inclusão previamente estabelecidos. Na base de dados LILACS encontramos quatro artigos, no MEDLINE dez, no CINAHL cinco, sendo que três artigos já haviam sido encontrados na base de dados MEDLINE e dois artigos no periódico BMT.

Para a extração de dados dos artigos incluídos na revisão integrativa, utilizou-se um instrumento previamente validado com autorização do autor ${ }^{(8)}$, o qual contempla os itens: identificação do artigo original, características metodológicas do estudo, avaliação do rigor metodológico, intervenções estudadas e resultados encontrados.

A análise dos dados extraídos foi realizada na forma descritiva, possibilitando ao enfermeiro avaliar a qualidade das evidências (nível de evidência disponível na literatura sobre o tema investigado, fornecer subsídios para a tomada de decisão no cotidiano da enfermagem, bem como a identificação de lacunas do conhecimento para o desenvolvimento de futuras pesquisas).

\section{RESULTADOS E DISCUSSÃO}

Os temas dos artigos foram: curativos (7), coleta de sangue (3), heparinização (1), manutenção, manuseio, prevenção e controle de infecção (7). Quanto à autoria dos artigos constatou-se que $9(50 \%)$ são de enfermeiros; 1 (6\%) foi escrito por médicos; $2(11 \%)$ foram feitos por enfermeiros e médicos; 2 (11\%) tinham como autores enfermeiros, médicos e outros profissionais da área da saúde; e em 4(22\%) não foi possível identificar a formação dos autores.

Em relação à instituição sede onde os estudos foram desenvolvidos, obteve-se 8 hospitais universitários, 5 hospitais, 2 universidades, 1 multicêntrico, 1 hospital em conjunto a um centro de pesquisa e 1 não possui identificação.

Quanto ao tipo de revista científica 7 eram publicações médicas, 6 de enfermagem oncológica, 3 de enfermagem geral, 1 de outras áreas de saúde e 1 dissertação de mestrado.

Ao analisar os delineamentos de pesquisa dos artigos incluídos, constatou-se $4(22,2 \%)$ ensaios clínicos randomizados, ou seja, delineamento de pesquisa experimental; $1(5,5 \%)$ pesquisa com delineamento quaseexperimental (estudo comparativo retrospectivo) e 13 $(72,2 \%)$ estudos com delineamento não-experimental, sendo $6(46,1 \%)$ tipo descritivo-exploratório, $1(7,6 \%)$ revisão da literatura/ survey, $1(7,6 \%)$ estudo de caso, 2 $(15,3 \%)$ survey e $3(23 \%)$ relatos de experiência.

Em relação à força das evidências constatou-se quatro artigos com nível de evidência 2, um artigo com nível de evidência 3 , nove com nível de evidência 4 e quatro com nível de evidência $5^{(9)}$.
Nas tabelas 1, 2, 3 e 4 apresenta-se a síntese dos artigos incluídos na presente revisão integrativa.

Quando comparados os diferentes tipos de cobertura para o curativo de cateter de Hickman, não foi encontrada, nos estudos, diferença estatisticamente significante na incidência de infecção relacionada ao cateter.

A vantagem demonstrada pelo curativo de poliuretano é a sua maior permanência, diminuindo a necessidade de trocas freqüentes e manipulação excessiva do óstio de saída do cateter. Além disso, também foi relatado maior satisfação e conforto do paciente, redução dos custos com material e menor necessidade da equipe de enfermagem.

Em pacientes submetidos ao TMO, a preocupação relacionada ao aparecimento de lesões causadas pela troca frequiente de curativos justifica-se, pela proliferação da microbiota local, que devido a falta da proteção inata da pele, torna difícil a sua remoção durante a anti-sepsia, aumentando o risco de complicações infecciosas. Dessa forma, seria favorável a implementação das evidências sobre o curativo de poliuretano que pode ser substituído a cada sete dias.

O Centers for Disease Control and Prevention (CDC) utiliza a seguinte classificação para os níveis de evidência: IA, fortemente recomendadas para implementação e fundamentadas em bons estudos experimentais, clínicos ou epidemiológicos; IB, fortemente recomendadas para implementação e fundamentadas em alguns estudos experimentais, clínicos ou epidemiológicos e em fortes modelos teóricos; IC, regras ou padronizações das regulamentações federais dos Estados Unidos da América (EUA); II, sugeridos para implementação e fundamentados em estudos clínicos ou epidemiológicos sugestivos ou em modelos teóricos; Problema sem desfecho, o CDC não encontra evidências que responderiam ao problema ${ }^{(17)}$.

As diretrizes do CDC para o curativo de cateteres tunelizados preconizam que o curativo de óstio pode ser, tanto com gaze estéril e esparadrapo, quanto com películas de poliuretano (evidência IA), sendo preferível o curativo com gaze estéril em pacientes com perspiração abundante, sangramento ou exsudação local (evidência II), refazer o curativo quando estiver úmido, solto, sujo ou na inspeção do local (evidência IA), nos cateteres tunelizados ou totalmente implantados a troca do curativo deve ser realizada uma vez na semana até que esteja cicatrizado (evidência IB) ${ }^{(17)}$.

$\mathrm{Na}$ anti-sepsia da pele há preferência pela solução clorexidina a $2 \%$, embora o PVPI alcoólico e aquoso ou o álcool a 70\% também possam ser utilizados (evidência IA), o óstio de cateteres tunelizados, quando bem cicatrizados, não necessitam de curativo (problema sem desfecho), não submergir o cateter em água, porém, banho de chuveiro é permitido se o cateter e suas conexões 
forem protegidos (evidência II), utilizar luvas limpas ou estéreis durante a troca do curativo (IC), sendo que o uso de luvas não substitui a higienização das mãos (evidência IA), não aplicar pomadas ou cremes antimicrobianos no sítio de inserção do cateter (exceto em cateter para hemodiálise), porque potencializa infec- ções fungicas e resistência microbiana (evidência IA), nenhuma recomendação pode ser feita para a utilização de suturas como dispositivo de segurança (problema sem desfecho), assegurar que o material utilizado para o curativo seja compatível com o material do cateter (evidência IB) ${ }^{(17)}$.

Tabela 1 - Síntese dos estudos experimentais sobre curativo do cateter venoso central (CVC) em pacientes submetidos ao TMO

\begin{tabular}{|c|c|c|c|c|}
\hline ESTUDO & TIPO/AMOSTRA & $\begin{array}{c}\text { INTERVENÇ̃̃O } \\
\text { ESTUDADA }\end{array}$ & RESULTADOS & CONCLUSỐES \\
\hline $\begin{array}{l}\text { Shivnan et al., } \\
1991^{(10)}\end{array}$ & $\begin{array}{l}\text { Ensaio clinico } \\
\text { randomizado prospectivo; } \\
98 \text { pacientes submetidos } \\
\text { ao TMO. }\end{array}$ & $\begin{array}{l}\text { Comparar o Tegadern (grupo } \\
\text { experimental/GE) com gaze estéril } \\
\text { ( grupo controle/GC). Anti-sepsia } \\
\text { com água oxigenada, seguida por } \\
\text { soluçâo de polivinilpirrolidona- } \\
\text { iodo (PVPI), após } 2 \text { minutos } \\
\text { aplicar pomada antimicrobiana. }\end{array}$ & $\begin{array}{l}\text { Infecção do óstio de saída do cateter } \\
\text { ocorreu em } 2 \text { dos } 51 \text { pacientes com } \\
\text { Tegaderm e em } 1 \text { de } 47 \text { com gaze } \\
\text { estéril. Um caso de sepse com } \\
\text { Tegaderm. Não houve diferença } \\
\text { estatisticamente significante nas taxas } \\
\text { de infeç̧ão entre os dois grupos de } \\
\text { curativos. }\end{array}$ & $\begin{array}{l}\text { Os autores afirmam que } \\
\text { o curativo com, } \\
\text { Tegaderm, parece ser } \\
\text { seguro, de custo- } \\
\text { beneficio melhor e } \\
\text { confortável para os } \\
\text { pacientes submetidos ao } \\
\text { TMO. }\end{array}$ \\
\hline $\begin{array}{l}\text { Brandt et al., } \\
1996^{(11)}\end{array}$ & $\begin{array}{l}\text { Ensaio clínico } \\
\text { randomizado prospectivo; } \\
101 \text { pacientes submetidos } \\
\text { ao TMO com cateter de } \\
\text { Hickman. }\end{array}$ & $\begin{array}{l}\text { Comparar o OpSite IV } 3000 \text { (GE) } \\
\text { e gaze estéril (GC). A anti-sepsia } \\
\text { da pele, ao redor do sítio de saída } \\
\text { do cateter, foi realizada com } 3 \\
\text { swabs de álcool a } 70 \% \text {, em } \\
\text { seguida } 3 \text { swabs de PVPI e após a } \\
\text { secagem passada pomada de } \\
\text { PVPI. }\end{array}$ & $\begin{array}{l}\text { Sepse ocorreu em } 10 \% \text { do grupo } \\
\text { experimental e } 2 \% \text { do controle. } \\
\text { Dentre os } 27 \text { pacientes com suspeita } \\
\text { de sepse, } 41 \% \text { eram do grupo } \\
\text { experimental e } 59 \% \text { do controle. A } \\
\text { infeção do túnel subcutâneo ocorreu } \\
\text { em } 5 \text { pacientes do grupo controle e } \\
\text { em } 3 \text { do experimental. Não houve } \\
\text { diferença estatisticamente significante } \\
\text { entre os dois grupos. }\end{array}$ & $\begin{array}{l}\text { Os autores afirmam que } \\
\text { os resultados apóiam a } \\
\text { conclusão de que os } \\
\text { custos podem ser } \\
\text { teduzidos com curativo } \\
\text { de poliuretano pela } \\
\text { menor frequieêncja de } \\
\text { troca. }\end{array}$ \\
\hline $\begin{array}{l}\text { Rasero et al., } \\
2000^{(12)}\end{array}$ & $\begin{array}{l}\text { Ensaio clínico } \\
\text { randomizado prospectivo; } \\
259 \text { pacientes submetidos } \\
\text { ao TMO. } \\
\text { Grupo A: CVC tunelizado } \\
\text { com curativo trocado a } \\
\text { cada } 5 \text { ou } 10 \text { dias. } \\
\text { Grupo B: CVC não } \\
\text { tunelizado com curativo } \\
\text { trocado a cada } 2 \text { ou } 5 \text { dias. }\end{array}$ & $\begin{array}{l}\text { Testar a freqüência da troca do } \\
\text { curativo com Tegaderm } \\
\text { relacionando a infeccăo local e a } \\
\text { toxicidade cutânea local. }\end{array}$ & $\begin{array}{l}\text { No grupo A, a infecção local oconreu } \\
\text { em } 12 \text { de } 79 \text { pacientes do grupo } 5 \text { dias } \\
\text { e } 13 \text { de } 81 \text { do grupo } 10 \text { dias. } \\
\text { Toxicidade cutânca grau } 0 \text { foi } \\
\text { registrada em } 86 \% \text { e } 87 \% \text { dos } \\
\text { curativos nos grupos } 5 \text { e } 10 \text { dias, } \\
\text { respectivamente. No Grupo B, a } \\
\text { infeç̧ão ocorreu em } 9 \text { de } 49 \text { pacientes } \\
\text { do grupo } 2 \text { dias e, também, em } 9 \\
\text { pacientes de } 50 \text { do grupo } 5 \text { dias. A } \\
\text { toxicidade cutânea, foi grau } 0 \text { em } 75 \% \\
\text { no grupo } 2 \text { dias e } 66 \% \text { no grupo } 5 \\
\text { dias. }\end{array}$ & $\begin{array}{l}\text { A análise dos dados } \\
\text { suporta a conclusão de } \\
\text { que as trocas de } \\
\text { curativos com intervalos } \\
\text { maiores são mais } \\
\text { confortáveis, reduzem a } \\
\text { toxicidade cutânea e não } \\
\text { há aumento das } \\
\text { complicações } \\
\text { infecciosas. }\end{array}$ \\
\hline $\begin{array}{l}\text { Benhamou et } \\
\text { al. } 2002^{(13)}\end{array}$ & $\begin{array}{l}\text { Ensaio clínico } \\
\text { randonizado prospectivo; } \\
112 \text { crianças submetidas } \\
\text { ao TMO. }\end{array}$ & $\begin{array}{l}\text { Testar a freqüência da troca a cada } \\
15 \text { (GE) dias versus } 4 \text { dias (GC) } \\
\text { dos curativos: Tegaderm para } \\
\text { toxicidade cutânea de graus } 0 \text { e } 1 \text {; } \\
\text { Mefix para toxicidade cutânea } \\
\text { graus } 2 \text { e } 3 \text {; gaze estéril e } \\
\text { esparadrapo para o grau } 4 .\end{array}$ & $\begin{array}{l}\text { Em } 17 \% \text { dos curativos do grupo } 15 \\
\text { dias, as trocas seguiram o protocolo } \\
\text { comparado a } 76 \% \text { no grupo } 4 \text { dias. } O \\
\text { grupo } 4 \text { dias demonstrou um risco } \\
\text { aumentado em } 3,4 \text { vezes para } \\
\text { toxicidade cutânea severa comparada } \\
\text { ao grupo } 15 \text { dias. Nenhum CVC foi } \\
\text { removido por infeç̧ão. }\end{array}$ & $\begin{array}{l}\text { A diminuição na } \\
\text { frequência de troca do } \\
\text { curativo reduziu a } \\
\text { toxicidade cutânea sem } \\
\text { aumentar o risco de } \\
\text { infecção local e } \\
\text { sistêmica }\end{array}$ \\
\hline $\begin{array}{l}\text { Rocha, } \\
2000^{(14)}\end{array}$ & $\begin{array}{l}\text { Estudo comparativo } \\
\text { retrospectivo. }\end{array}$ & $\begin{array}{l}\text { Comparar o anti-séptico } \\
\text { clorexidina alcoólica a } 0,5 \% \\
(\mathrm{CHX}) \text { com o PVPI aquoso a } \\
10 \% \text {. }\end{array}$ & $\begin{array}{l}\text { O grupo CHX recebeu tnais dias de } \\
\text { antibiótico em ambulatório, } \\
\text { demonstrando uma diferença } \\
\text { estatisticamente significante com o } \\
\text { grupo PVPI. } \\
\text { No grupo PVPI } 38 \text { pacientes } \\
\text { apresentaram infeç̧ão. No grupo } \\
\text { CHX } 1 \text { paciente apresentou infecção. }\end{array}$ & $\begin{array}{l}\text { A incidência de infeção } \\
\text { foi maior no grupo PVPI, } \\
\text { porém não se pode } \\
\text { afirmar que a CHX foi o } \\
\text { único responsável pela } \\
\text { diminuição da infecção }\end{array}$ \\
\hline
\end{tabular}

Tabela 2 - Síntese dos estudos descritivos sobre curativo do CVC em pacientes submetidos ao TMO

\begin{tabular}{|c|c|c|c|c|}
\hline ESTUDO & TIPO/ AMOSTRA & $\begin{array}{c}\text { INTERVENCẼO } \\
\text { ESTUDADA }\end{array}$ & RESULTADOS & CONCLUSÕES \\
\hline $\begin{array}{l}\text { Wilson, } \\
1995^{(15)}\end{array}$ & $\begin{array}{l}\text { Estudo descritivo- } \\
\text { exploratório; } 12 \\
\text { pacientes submetidos ao } \\
\text { TMO com cateter de } \\
\text { Hickman. }\end{array}$ & $\begin{array}{l}\text { Aplicar Duoderm para fixar o } \\
\text { esparadrapo. }\end{array}$ & $\begin{array}{l}10 \text { de } 12 \text { participantes não } \\
\text { apresentaram efeitos adversos na } \\
\text { pele durante ou após a utilização do } \\
\text { Duoderm. }\end{array}$ & $\begin{array}{l}\text { A utilização do Duoderm é } \\
\text { uma proteção para a pele, } \\
\text { pois evita a sua irritação pelo } \\
\text { esparadrapo. }\end{array}$ \\
\hline $\begin{array}{l}\text { Zitella, } \\
2003^{(16)}\end{array}$ & $\begin{array}{l}\text { Revisão da } \\
\text { literatura/survey; } \\
26 \text { artigos e } 30 \text { centros } \\
\text { de TMO. }\end{array}$ & $\begin{array}{l}\text { Identificar artigos de cuidados } \\
\text { com CVC em pacientes } \\
\text { submetidos ao TMO. Identificar } \\
\text { as práticas utilizadas nos } \\
\text { cuidados com CVCs pelos } \\
\text { Membros do Grupo de interesse } \\
\text { especial por TMO da Sociedade } \\
\text { de Enfermagem Oncológica. }\end{array}$ & $\begin{array}{l}\text { Os estudos recomendam os } \\
\text { curativos de poliuretano por reduzir } \\
\text { a irritação da pele e seu custo- } \\
\text { beneficio melhor. As práticas } \\
\text { evidenciaram que } 53 \% \text { utilizam o } \\
\text { PVPI alcoólico; } 80 \% \text { utilizam o } \\
\text { curativo de poliuretano, sendo a } \\
\text { troca semanal } 46 \% \text {; no curativo } \\
\text { com gaze estéril, a troca é diária em } \\
80 \% \text {. }\end{array}$ & $\begin{array}{l}\text { O curativo de poliuretano } \\
\text { com troca semanal mostra-se } \\
\text { seguro e eficiente para } \\
\text { pacientes submetidos ao } \\
\text { TMO. }\end{array}$ \\
\hline
\end{tabular}


As soluções iodadas possuem agentes microbicidas de ação imediata após o contato de dois a cinco minutos e amplo espectro de microrganismos. O seu efeito residual varia de 30 minutos a uma hora dependendo da absorção de iodo pela pele, sem contudo atingir níveis sistêmicos ${ }^{(18)}$.

Outro agente microbicida importante é a clorexidina, sua ação em baixas concentrações é bacteriostática, mas em concentrações elevadas tem uma rápida ação bactericida. As vantagens da clorexidina são sua imediata ação bactericida, após quinze segundos, e um efeito residual prolongado podendo chegar a seis horas ${ }^{(18)}$.

Apesar destas recomendações, os aspectos relacionados ao tipo de cobertura e a freqüência da troca do curativo do cateter venoso central apresentam controvérsias, na literatura há artigos com diferentes conclusões.

Em uma pesquisa com delineamento quase-experimental, os autores testaram quatro tipos de curativos, a saber: PVPI e tegaderm, PVPI e gaze estéril, clorexidina e tegaderm, clorexidina e gaze estéril, as trocas dos curativos estavam programadas para as segundas-feiras, quartas-feiras e sextas-feiras. A amostra foi reduzida, participaram 60 crianças advindas das unidades de oncologia e de TMO. Não houve diferença estatisticamente significante entre os grupos quanto ao crescimento bacteriano, os resultados apontaram um aumento na frequiência de hiperemia e edema local quando a solução anti-séptica utilizada era o PVPI sugerindo um aumento da irritação da pele ${ }^{(19)}$.

Por outro lado, um estudo também com delineamento quase-experimental foi realizado com 32 pacientes com doenças hematológicas malignas e não-malignas, com cateter venoso central de única via, comparando a troca do curativo de Tegaderm semanal versus duas vezes na semana, na incidência de infecção em pacientes. O grupo que tinha a troca semanal do curativo apresentou um número maior de culturas da ponta do cateter positivas e uma tendência para a troca extra do curativo, cultura da pele com um maior número de colônias, período menor para ocorrência de infecção do óstio de cateter e septicemias por gram-positivos, quando comparado ao grupo que trocava o curativo duas vezes na semana ${ }^{(20)}$.

Tabela 3 - Síntese dos estudos descritivos sobre coleta de sangue e protocolo de heparinização do CVC em pacientes submetidos ao TMO

\begin{tabular}{|c|c|c|c|c|}
\hline ESTUDO & TIPO/ AMOSTRA & $\begin{array}{c}\text { INTERVENÇÃO } \\
\text { ESTUDADA }\end{array}$ & RESULTADOS & CONCLUSÕES \\
\hline $\begin{array}{l}\text { Busca et al., } \\
1994^{(22)}\end{array}$ & $\begin{array}{l}\text { Estudo descritivo- } \\
\text { exploratório; } 8 \text { pacientes } \\
\text { submetidos ao TMO } \\
\text { alogênico } \\
\text { hospitalizados. }\end{array}$ & $\begin{array}{l}\text { Mensurar concentrą̧̃es de } \\
\text { ciclosporina (CSA) } \\
\text { simultaneamente da via do cateter } \\
\text { de Hickman utilizada para a infusão } \\
\text { da CSA (via + CSA), da segunda } \\
\text { via não utilizada para infusão de } \\
\text { CSA (via - CSA) e de uma veia } \\
\text { periférica. }\end{array}$ & $\begin{array}{l}\text { As concentrações séricas de CSA } \\
\text { em amostras oriundas da via }+ \\
\text { CSA foram significativamente } \\
\text { maiores que nas da via - CSA ou } \\
\text { da veia periférica. }\end{array}$ & $\begin{array}{l}\text { Coletar amostra de sangue } \\
\text { para monitorizar nível } \\
\text { sérico de CSA por meio da } \\
\text { via não utilizada para } \\
\text { infusão de CSA. }\end{array}$ \\
\hline $\begin{array}{l}\text { Claviez et al., } \\
2002^{(23)}\end{array}$ & Estudo de caso. & $\begin{array}{l}\text { Identificar as concentrações séricas } \\
\text { de CSA em amostras de sangue } \\
\text { coletadas das vias (A e B) do CVC e } \\
\text { da veia periférica após duas } \\
\text { semanas da transição da CSA } \\
\text { endovenosa (EV) para a CSA oral } \\
\text { (VO). }\end{array}$ & $\begin{array}{l}\text { A CSA EV foi administrada na via } \\
\text { B. O paciente estava fazendo uso } \\
\text { de CSA por via oral e uma amostra } \\
\text { para mensurar a CSA foi coletada } \\
\text { da via B e o exame resulton em um } \\
\text { nivel > } 500 \mathrm{ng} / \mathrm{ml} \text {. Uma amostra } \\
\text { foi coletada da via A e o nível foi } \\
\text { de } 118 \mathrm{ng} / \mathrm{ml} \text {. Amostras da via B } \\
\text { mostraram-se falsamente elevadas } \\
\text { até } 9 \text { semanas após a últina } \\
\text { infusão de CSA. }\end{array}$ & $\begin{array}{l}\text { O nivel de CSA obtido do } \\
\text { CVC deve ser interpretado } \\
\text { cautelosamente quando } \\
\text { valores discrepantes são } \\
\text { observados entre a dose } \\
\text { administrada e a } \\
\text { mensuração da droga. } \\
\text { Nesta situação, uma } \\
\text { amostra de sangue } \\
\text { coletada em veia periférica } \\
\text { pode evitar um resultado } \\
\text { errôneo. }\end{array}$ \\
\hline $\begin{array}{l}\text { Keller, } \\
1994^{(24)}\end{array}$ & $\begin{array}{l}\text { Estudo survey } \\
\text { descritivo; } 34 \text { centros } \\
\text { pediátricos de TMO. }\end{array}$ & $\begin{array}{l}\text { Levantar o método de coleta de } \\
\text { sangue pelo cateter de Hickman em } \\
\text { crianças submetidas ao TMO. Os } \\
\text { métodos são: descarte, reinfusão e } \\
\text { mistura. }\end{array}$ & $\begin{array}{l}\text { A maioria dos centros consultados } \\
\text { utiliza o método de descarte. } 0 \\
\text { volume descartado variou de } 0,5 \text { a } \\
10 \text { ml. As preocupações } \\
\text { relacionadas ao método de coleta } \\
\text { de sangue citadas mais } \\
\text { frequientemente foram: o risco de } \\
\text { infecção, perda de sangue e } \\
\text { acurácia dos valores laboratoriais. }\end{array}$ & $\begin{array}{l}\text { Um estudo prospectivo } \\
\text { randomizado testando um } \\
\text { dos três métodos em uma } \\
\text { amostra grande se faz } \\
\text { necessário para estabelecer } \\
\text { um protocolo de práticas } \\
\text { ideais. }\end{array}$ \\
\hline $\begin{array}{l}\text { Kelly et al., } \\
1992^{(25)}\end{array}$ & $\begin{array}{l}\text { Estudo descritivo- } \\
\text { exploratório } \\
\text { retrospectivo e } \\
\text { prospectivo; } 89 \mathrm{CVCs} \\
\text { em pacientes submetidos } \\
\text { e não submetidos ao } \\
\text { TMO. }\end{array}$ & $\begin{array}{l}\text { Avaliar o protocolo de } \\
\text { heparinização semanal do CVC em } \\
\text { pacientes ambulatoriais. O novo } \\
\text { protocolo consistiu na administração } \\
\text { de } 5 \mathrm{ml} \text { de solução salina com } \\
\text { heparina } 10 \mathrm{U} / \mathrm{ml} \text {, em cada via do } \\
\text { cateter, uma vez por semana. }\end{array}$ & $\begin{array}{l}\text { A taxa global de infecção foi } 19,1 \\
\% \text { ou } 0,15 / 100 \text { cateteres dia. } \\
\text { Correspondendo a } 0,25 / 100 \\
\text { cateteres dia em pacientes } \\
\text { submetidos ao TMO e } 0,07 / 100 \\
\text { cateteres dia em pacientes não } \\
\text { submetidos ao TMO. A alteração } \\
\text { na permeabilidade do CVC ocorreu } \\
\text { em } 13,5 \% \text {, sendo necessária } \\
\text { alteração no protocolo de } \\
\text { heparinização. A permanência } \\
\text { média do CVC foi de } 177 \text { dias. } \\
\text { microrganismo mais identificado } \\
\text { foi Staphylococcus epidermidis } \\
\text { isolado em } 58,5 \% \text {. }\end{array}$ & $\begin{array}{l}\text { O risco de complicações } \\
\text { infecciosas em pacientes } \\
\text { submetidos ao TMO foi } \\
\text { maior do que nos pacientes } \\
\text { submetidos à } \\
\text { quimioterapia } \\
\text { convencional. As taxas de } \\
\text { infecção encontradas são } \\
\text { semelhantes às descritas na } \\
\text { literatura, assim } \\
\text { concluíram que a } \\
\text { utilização do novo } \\
\text { protocolo de heparinização } \\
\text { semanal é uma prática } \\
\text { segura. }\end{array}$ \\
\hline
\end{tabular}


Na literatura constatamos uma revisão sistemática sobre curativos de cateter venoso central, avaliando oito estudos, dentre eles, o número 2 anteriormente descrito; os autores ao final, concluíram que tal assunto desperta um alto nível de incerteza sobre o risco de infecção e que a escolha do curativo baseia-se na preferência do paciente e da equipe. Embora o estudo não tenha avaliado pacientes exclusivos de TMO e sim, pacientes submetidos a implante de cateter venoso central de qualquer tipo $^{(21)}$.

Frente a análise dos artigos incluídos nesta revisão integrativa, recomenda-se a utilização de curativos com poliuretano, trocados a cada sete dias, com o uso de clorexidina, como agente anti-séptico para os pacientes submetidos ao TMO.

$\mathrm{O}$ método de coleta de sangue por meio do CVC mais observado é o de descarte, tanto para crianças quanto para adultos. $\mathrm{O}$ volume de sangue preconizado para descarte da via fechada ou da que se encontra com infusão de medicamentos é variável. Este cuidado deve-se a preocupação com a contaminação da amostra de sangue por eletrólitos ou outros elementos presentes na solução previamente infundida.

Em um estudo comparativo prospectivo não randomizado para determinar o volume de sangue que deve ser descartado antes de se obter a amostra para os exames de tempo de protombina (TP) e tempo de tromboplastina parcialmente ativada (TTPA), todas as amostras foram obtidas de uma via fechada com solução com heparina, sendo que somente após o descarte do volume de $25 \mathrm{ml}$ o exame mostrou-se $95 \%$ confiável, podendo ser utilizado clinicamente ${ }^{(26)}$.

Quanto à coleta de sangue para mensurar o nível sérico de ciclosporina (CSA), a recomendação de um padrão de via exclusiva para CSA deverá ser estabelecida para assegurar a acurácia do resultado e não comprometer o tratamento.

Considerando os estudos incluídos na revisão integrativa, refletimos que dependendo do tipo de exame, o volume que deve ser descartado tem variações para reduzir ou evitar a ocorrência de interações medicamentosas no interior da via do cateter.

Em relação ao protocolo de heparinização um estudo de coorte avaliou a incidência de trombose relacionada aos cateteres tunelizados em pacientes que receberam a infusão de $5 \mathrm{ml}$ da solução salina com heparina $10 \mathrm{U} / \mathrm{ml}$ (50U) e de $10 \mathrm{ml}$ da solução salina com heparina $100 \mathrm{U} /$ $\mathrm{ml}$ (1000U). Os resultados demonstraram que não houve diferença estatisticamente significante entre os dois protocolos de heparinização, sendo a menor concentração de heparina tão efetiva quanto a maior na prevenção de trombose ${ }^{(27)}$.

Considerando que a terapia endovenosa intermitente é amplamente utilizada e que, para tal, é necessária a manutenção de um cateter permeável, entendemos que um protocolo de heparinização oferece vantagens, como permitir a coleta de sangue eliminando múltiplas punções e propiciar acesso para a administração de medicamentos de emergência.

Apesar das variações nos protocolos de heparinização quanto ao volume, concentração e frequiência; uma revisão integrativa da literatura que avaliou seis estudos de heparinização dos cateteres tunelizados recomendou a infusão rápida de $5 \mathrm{ml}$ da solução salina com heparina, na concentração de $10 \mathrm{U} / \mathrm{ml}$, ou seja, $50 \mathrm{U}$ de heparina infundida em cada via, sendo que a freqüência variou de uma a duas vezes na semana ${ }^{(28)}$.

Semelhante ao que ocorre mundialmente, a infecção relacionada ao cateter é uma das principais complicações do TMO, é de se esperar esforços da equipe de saúde para a sua prevenção. A elaboração da presente revisão integrativa, auxilia na reflexão sobre as condutas adotadas atualmente, obrigando, muitas vezes, a adequação de intervenções para a melhoria da assistência prestada ao paciente.

Mantendo tal objetivo, a busca de evidências na literatura para guiar esta empreitada, frente aos estudos incluídos nesta revisão, principalmente sobre manipulação, manuseio, prevenção e controle de infecção, notou-se que as evidências encontradas são fracas, para a elaboração de recomendações para a prática clínica.

Sendo assim, concluiu-se que, por enquanto, o protocolo que se mostra embasado em fortes evidências, no contexto de prevenção e controle de infecções relacionadas a cateter venoso central são as diretrizes do $\mathrm{CDC}^{(17)}$, atualmente preconizadas em todo território norte-americano. Ressalta-se, que não são direcionadas apenas aos pacientes submetidos ao TMO, sendo essa, uma clientela diferenciada, ou seja, são mais expostos aos riscos de infecção, pois suas defesas inatas estão abolidas.

As diretrizes aplicáveis nos cuidados com o cateter tunelizado do protocolo de prevenção e controle de infecção, preconizadas pelo CDC são: acompanhar as taxas de infecção de corrente sangüínea relacionadas ao cateter venoso central e identificar as falhas nas práticas de controle de infecção (evidência IA), utilizar um cateter com o mínimo de vias necessárias para atender as necessidades do tratamento proposto (evidência IB), designar uma via do cateter para infusão exclusiva de NPP em cateteres de múltiplas vias (evidência II), não injetar profilaticamente soluções contendo antibiótico nas vias do cateter, excetuando para o tratamento de pacientes que possuem cateteres de longa permanência tunelizados totalmente implantados ou semiimplantados com história de múltiplas infecções, apesar da utilização de medidas assépticas adequadas (evidência II) ${ }^{(17)}$. 
Tabela 4 - Síntese dos estudos descritivos sobre manutenção, manuseio, prevenção e controle de infecção do CVC em pacientes submetidos ao TMO

\begin{tabular}{|c|c|c|c|c|}
\hline ESTUDO & TIPO/ AMOSTRA & $\begin{array}{c}\text { INTERVENÇÃO } \\
\text { ESTUDADA }\end{array}$ & RESULTADOS & CONCLUSÕES \\
\hline $\begin{array}{l}\text { Teitelbaum et } \\
\text { al., } 1987^{(29)}\end{array}$ & $\begin{array}{l}\text { Estudo descritivo- } \\
\text { exploratório } \\
\text { retrospectivo; } 10 \\
\text { pacientes submetidos } \\
\text { ao TMO. }\end{array}$ & $\begin{array}{l}\text { Implantar adicionalmente um cateter } \\
\text { dupla via, Quinton, para a infusão } \\
\text { da nutrição parenteral prolongada } \\
\text { (NPP) ocorrer sem interrupções. }\end{array}$ & $\begin{array}{l}\text { Picos febris ocorreram em } 4 \\
\text { sujeitos, porém não houve } \\
\text { evidência de sepse ou hemocultura } \\
\text { positiva. } 2 \text { sujeitos tiveram } \\
\text { alterações na pele ao redor do sitio } \\
\text { de saida do cateter que com o } \\
\text { cuidado local eficiente cessaram- } \\
\text { se os sinais. A infusão da NPP não } \\
\text { foi interrompida. }\end{array}$ & $\begin{array}{l}\text { A utilização de cateteres de } \\
\text { três vias elimina qualquer } \\
\text { interrupção na infusão da } \\
\text { NPP e diminui a } \\
\text { manipulação minimizando } \\
\text { os riscos de infeç̧ão. }\end{array}$ \\
\hline $\begin{array}{l}\text { Toyonaga et al., } \\
1988^{(36)}\end{array}$ & $\begin{array}{l}\text { Estudo descritivo- } \\
\text { exploratório } \\
\text { retrospectivo; } 112 \\
\text { cateteres en pacientes } \\
\text { submetidos ao TMO. }\end{array}$ & $\begin{array}{l}\text { Identificar retrospectivamente as } \\
\text { complicações relacionadas ao uso } \\
\text { dos cateteres venosos centrais }\end{array}$ & $\begin{array}{l}\text { Foram realizadas } 112 \\
\text { cateterizações, dessas, } 30 \\
\text { utilizaram cateteres reutilizados; } \\
13 \text { apresentaram complicações, } \\
\text { sendo que } 9 \text { eram cateteres novos } \\
\text { e } 4 \text { cateteres eram reutilizados. } \\
\text { Três pacientes apresentaram } \\
\text { infecção do túnel subcutâneo e } \\
\text { septicemia e evoluíram para o } \\
\text { óbito, sendo } 2 \text { do grupo com } \\
\text { cateter novo e } 1 \text { com cateter } \\
\text { reutilizado. }\end{array}$ & $\begin{array}{l}\text { O número de cateterizações } \\
\text { não é suficiente para } \\
\text { estabelecer associações entre } \\
\text { os fatores desencadeadores } \\
\text { das complicações. }\end{array}$ \\
\hline $\begin{array}{l}\text { Karrei, } \\
1982^{(31)}\end{array}$ & Relato de experiência. & $\begin{array}{l}\text { Relatar a prevenção de problemas } \\
\text { com o cateter de Hickman. }\end{array}$ & $\begin{array}{l}\text { Os problemas observados foram: } \\
\text { oclusão do cateter, infecções do } \\
\text { sítio de sáda do cateter e da } \\
\text { incisão, e intraluminal, } \\
\text { rompimento ou furo no cateter, } \\
\text { embolismo aéreo e dificuldade } \\
\text { para coleta de sangue pelo cateter. } \\
\text { O flush com água estéril entre as } \\
\text { adninistrações de medicaçes } \\
\text { evita a oclusão. Utilizar técnica } \\
\text { asséptica para troca do curativo ou } \\
\text { manipulação do cateter minimiza a } \\
\text { infecção. }\end{array}$ & $\begin{array}{l}\text { A utilização do cateter de } \\
\text { Hickman foi positiva, pois a } \\
\text { maioria dos cateteres não } \\
\text { apresenta complicações. A } \\
\text { equipe de enfermagem } \\
\text { considera o cateter um } \\
\text { acesso venoso seguro e } \\
\text { rápido e o paciente sente-se } \\
\text { beneficiado pelo cateter pois } \\
\text { o torna mais independente. }\end{array}$ \\
\hline Silva, $1994^{(33)}$ & Relato de experiência. & $\begin{array}{l}\text { Descrever as técnicas de } \\
\text { manipulação e manuseio do cateter } \\
\text { de Hickman. }\end{array}$ & $\begin{array}{l}\text { Higienização das mãos, proteção } \\
\text { das partes desconectadas com } \\
\text { gazes estéreis, infusões de } \\
\text { soluções de diferentes densidades } \\
\text { e/ou incompativeis em vias } \\
\text { separadas, soluções salinas com } \\
\text { heparina na concentração } 100 \\
\text { U/ml, curativos com PVPI tópico } \\
\text { e gaze estéril são medidas } \\
\text { importamtes que devem ser } \\
\text { adotadas na utilização do cateter } \\
\text { de Hickman. }\end{array}$ & $\begin{array}{l}\text { A equipe de saúde deve ser } \\
\text { adequadamente preparada, a } \\
\text { fim de que a manipulação do } \\
\text { cateter de Hickman seja } \\
\text { isenta de riscos, oferecendo } \\
\text { maior segurança para o } \\
\text { paciente. }\end{array}$ \\
\hline $\begin{array}{l}\text { Anders et al., } \\
2000^{(34)}\end{array}$ & Relato de experiência. & $\begin{array}{l}\text { Descrever as rotinas relacionadas ao } \\
\text { cateter de Hickman. }\end{array}$ & $\begin{array}{l}\text { Os autores consideram que o } \\
\text { curativo, a heparinização e o } \\
\text { sistema Interlink são os três } \\
\text { principais cuidados com o cateter } \\
\text { de longa permanência. }\end{array}$ & $\begin{array}{l}\text { A infeç̧ão é uma } \\
\text { complicação limitante ao } \\
\text { uso do cateter. Os princípios } \\
\text { de assepsia no manuseio do } \\
\text { cateter para o controle das } \\
\text { infeções devem ser } \\
\text { adotados de forma conjunta } \\
\text { pela equipe de saíde. }\end{array}$ \\
\hline
\end{tabular}


A troca das conexões deve ser feita a cada 72 horas, incluindo os dispositivos do sistema fechado (evidência IA), se a solução infundida for de dextrose e aminoácidos, os dispositivos para infusão devem ser trocados, também, a cada 72 horas (evidência II), a troca dos equipos para administração de sangue, seus derivados e soluções lipídicas deve ser dentro de 24 horas (evidência IB), realizar a desinfecção dos injetores com álcool a $70 \%$ ou PVPI antes de perfurá-los (evidência IA), realizar a higienização das mãos com sabão anti-séptico ou álcoolgel antes e depois de manusear o acesso venoso (evidência IA). Apesar, dessas recomendações estarem disponíveis e serem de fácil utilização, ainda percebemos inconsistência nas práticas relacionadas aos acessos vasculares ${ }^{(17)}$.

Em um survey sobre as práticas relacionadas aos cateteres venosos centrais em unidades de terapia intensiva; os autores ao compararem os dados evidenciados no estudo com as diretrizes do CDC, detectaram que os profissionais não incorporam as evidências na sua prática clínica e concluíram que uma melhor adesão ao protocolo poderia ajudar a padronização da melhor prática e facilitar o cuidado baseado em evidências ${ }^{(36)}$.

Dentre as condições comumente associadas ao risco para o desenvolvimento de infecção relacionada ao cateter tunelizado o número de manipulações é o fator predisponente de maior risco para o desenvolvimento de infecção( ${ }^{(4)}$.

Os estudiosos sobre infecção de cateter afirmam que o treinamento adequado no procedimento de manipulação do cateter é a medida mais eficaz na prevenção de bacteremias associadas, tendo em vista que sua manipulação e a habilidade de quem o faz são os fatores de risco mais importantes para o desenvolvimento dessas complicações, justificando a importância de uma padronização.

\section{CONCLUSÕES}

Em relação ao procedimento curativo, o paciente submetido ao TMO seria beneficiado pela utilização do curativo de poliuretano, pois a troca com intervalos maiores previne a toxicidade cutânea, aumentando a satisfação e o conforto do paciente e reduzindo o tempo de enfermagem.

O método de descarte para a coleta de sangue por meio do CVC cessa a influência dos elementos presentes na via garantindo a acurácia do exame. O principal risco deste método é um possível prejuízo na hematimetria do paciente. No entanto, a coleta de sangue para a dosagem de CSA da via pela qual foi infundida, resultará num valor falsamente elevado, mesmo utilizando o método de descarte.

O protocolo de heparinização para a manutenção da permeabilidade consiste na infusão rápida de $5 \mathrm{ml}$ da solução salina com heparina, na concentração de $10 \mathrm{U} /$ $\mathrm{ml}$ em cada via, sendo que a freqüência pode ser de uma a duas vezes na semana.

Em relação a manipulação, manuseio, prevenção e controle de infecção relacionados ao cateter, o objetivo é reduzir o número de manipulações ou aberturas das vias para o meio externo. O treinamento da equipe de saúde para a manipulação do cateter é considerado uma medida eficaz na prevenção de infecção.

As diretrizes do CDC estão alicerçadas em fortes evidências e a sua utilização é a melhor escolha para a padronização dos cuidados de enfermagem, até que novos estudos que retratem evidências fortes sejam desenvolvidos, exclusivamente em pacientes submetidos ao TMO.

\section{REFERÊNCIAS}

1. Nelson JL, Torrez R, Louie FM, Choe OS, Storb R, Sullivan KM. Pre-existing auto-immune disease in patients with long term survival after allogenic marrow transplantion. J Rheumatol. 1997; 24 Suppl 48:23-9.

2. Ray S, Stacey R, Imrie M, Filshie J. A review of 560 Hickman catheter insertions. Anaesthesia. 1996;51(10):981-5.

3. Fulton JS. Long-term vascular access devices. Annu Rev Nurs Res. 1997;15:237-62.

4. Castagnola E, Molinari AC, Fratino G, Viscoli C. Conditions associated with infections of indwelling central venous catheters in cancer patients: a summary. Br J Haematol. 2003;121(2): 233-9.

5. Galvão CM. A prática baseada em evidências: uma contribuição para a melhoria da assistência de enfermagem perioperatória [tese]. Ribeirão Preto (SP): Escola de Enfermagem de Ribeirão Preto/USP; 2002.

6. Broome M. Integrative literature reviews in the development of concepts. In: Rodgers BL, Knafl KA. Concept development in nursing: foundations, techniques and applications. Philidelphia: WB Saunders;1993. p.193-215.

7. Beyea SC, Nicoll LH. Writing an integrative review. AORN J. 1998; 67(4):877-80.

8. Ursi ES. Prevenção de lesões de pele no perioperatório: revisão integrativa da literatura [tese]. Ribeirão Preto (SP): Escola de Enfermagem de Ribeirão Preto/USP; 2005.

9. Stetler CB, Morsi D, Rucki S, Broughton S, Corrigan B, Fitsgerald $\mathrm{J}$ el al. Utilization focused integrative reviews in a nursing service. Appl Nurs Res. 1998;11(4):195-206.

10. Shivnan JC, MCguire D, Freedman S, Sharkazy E, Bosserman G, Larson E et al. A comparison of transparent adherent and dry sterile gauze dressings for long-term central catheters in patients undergoing bone marrow transplant. Oncol Nurs Forum. 1991;18(8):1349-56. 
11. Brandt B, DePalma J, Irwin M, Shogan J, Lucke JF. Comparison of central venous catheter dressing in bone marrow transplant recipients. Oncol Nurs Forum. 1996;23(5): 829-36.

12. Rasero L, Degl'Innocenti M, Mocali M, Alberani F, Boschi S, Giraudi A et al. Comparison of two different protocols for central venous catheter dressing in bone marrow transplant patients: results of a randomized multicenter study. Haematologica. 2000;85(3):275-9.

13.Benhamou E, Fessard E, Com-Nougué C, Beaussier PS, Nitenberg G, Tancrède $\mathrm{C}$ et al. Less frequent catheter dressing changes decrease local cutaneous toxicity of high-dose chemotherapy in children, without increasing the rate of catheter-related infections: results of a randomized trial. Bone Marrow Transplant. 2002;29(8):653-8.

14. Rocha IF. Infecção no local de saída e túnel subcutâneo de cateteres tipo Hickman em pacientes de transplante de medula óssea alogênico, relacionado aos anti-sépticos a base de polivinilpirrolidona-iodo e gluconato de clorexidina [tese] São Paulo (SP): Escola de Enfermagem da USP; 2000.

15. Wilson KE. Duoderm reduces skin breakdown at catheter exit site. Oncol Nurs Forum. 1995;22(4):829-36.

16. Zitella L. Central venous catheter site care for blood and marrow transplant recipients. Clin J Oncol Nurs. 2003;7(3):289-98.

17. Centers for Disease Control and Prevention. Guidelines for the prevention of intravascular catheter-related infections. MMWR Recomm Rep. 2002;51(RR-10):1-29.

18. Graziano RU, Silva A, Bianchi ERF. Limpeza, desinfecção, esterilização de artigos e anti-sepsia. In: Fernandes AT, organizador. Infecção hospitalar e suas interfaces na área da saúde. São Paulo: Atheneu; 2000. p. 266-305.

19. Freiberger D, Bryant J, Marino B. The effects of different central venous line dressing changes on bacterial growth in a pediatric oncology population. J Pediatr Oncol Nurs. 1992; 9(1):3-7.

20. Engervall P, Ringertz S, Hagman E, Skogman K, Björkholm M. Change of central venous catheter dressings twice a week is superior to once a week in patients with haematological malignances. J Hosp Infect. 1995;29(4):275-86.

21. Gillies D, O'Riordan E, Carr D, O’Brien I, Frost J, Gunning R. Central venous catheter dressings: a systematic review. J Adv Nurs. 2003;44(6):623-32.

22. Busca A, Miniero R, Vassallo E, Leone L, Oddenino O, Madon E. Monitoring of cyclosporine blood levels from central venous lines: a misleading assay? Ther Drug Monit. 1994;16(1):71-4.

23. Claviez A, Glass B, Dreger P, Suttorp M. Elevated blood drug levels obtained from indwelling silicon catheters during oral cyclosporine A administration. Bone Marrow Transplant. 2002; 29(6):535-6.
24. Keller CA. Methods of drawing blood samples through central venous catheters in pediatric patients undergoing bone marrow transplant: results of a national survey. Oncol Nurs Forum. 1994;21(5):879-84.

25. Kelly C, Dumenko L, Mcgregor SE, Mchutchion ME. A change in flushing protocols of central venous catheters. Oncol Nurs Forum. 1992;19(4):599-605.

26. Mayo DJ, Dimond EP, Kramer W, Horne MK. Discard volumes necessary for clinically useful coagulation studies from heparinized Hickman catheters. Oncol Nurs Forum. 1996; 23(4):671-5.

27. Brown-Smith JK, Stoner MH, Barley ZA. Tunneled catheter thrombosis: factors related to incidence. Oncol Nurs Forum. 1990;17(4):543-9.

28. Buswell L, Beyea SC. Flushing protocols for tunneled central venous catheters: an integrative review of the literature. J Knowl Synth Nurs. [serial on the Internet]. 1998 [cited 2005 Feb 1]; 5(3): [about 1 p.]. Available from: http://www. stti. iupui. edu/ library/ojksn/articles/050003.pdf

29. Teitelbaum DH, Fabri PJ, Kudsk KA, Tutschka P. Single plus double lumen intra-atrial venous access in bone marrow transplantation recipients. Surg Gynecol Obstet. 1987;164 (4):387-8.

30. Toyonaga ET, Veran MP, Pasquini R, Neto JZ. Complicações do uso de cateteres venosos centrais de longa permanência em transplante de medula óssea. Rev Paul Enferm. 1988; 8(2): 23-8.

31. Karrei I. Hickman catheters your guide to troublefree use. Can Nurse. 1982;78(11): 25-7.

32. Richard-Smith A, Buh S. Reducing central line catheter infections in bone marrow transplant patients. Nurs Clin North Am. 1995;30(1):45-52.

33. Silva RJ. Manuseio do cateter de Hickman pela enfermagem: estudo observacional. Rev Soc Cardiol Estado de São Paulo. 1994;4(Supl 1)A:1-4.

34. Anders JC, Soler VM, Brandão EM, Vendramini EC, Bertagnolli CLS, Giovani PG et al. Aspectos de enfermagem, nutrição, fisioterapia e serviço social no transplante de medula óssea. Medicina. 2000;33(4):463-85.

35. Guerrato R, Biagi MC. The central venous catheter in a bone marrow unit: an unresolved problem. Haematologica. 2000; 85(Supl 11):62-5.

36. Rickard CM, Courtney M, Webster J. Central venous catheters: a survey of ICU practices. J Adv Nurs. 2004;48(3):247-56. 